\title{
THE STUDENT ADAPTATION TO COLLEGE QUESTIONNAIRE (SACQ) FOR USE WITH SPANISH STUDENTS
}

\author{
Authors: Rodríguez González María Soledad, Tinajero Vacas Carolina, Guisande Couñago \\ María Adelina, and Paramo Fernández María Fernanda
}

This is the peer reviewed version of the following article: Rodríguez-González, M.S., Tinajero, C., Guisande, M.A. \& Páramo, M.F. (2012). The Student Adaptation to College Questionnaire (SACQ) for use with Spanish Students. Psychological Reports, 11, 624 640. doi: 10.2466/08.10.20.PR0.111.5.624-640

This article may be used for non-commercial purposes in accordance with Ammons Scientific and SAGE Publications terms and conditions for use of self-archived versions. 


\section{The student adaptation to college questionnaire}

\section{(sacq) for use with spanish students}

Authors: Rodríguez González María Soledad, Tinajero Vacas Carolina, Guisande Couñago María Adelina, and Paramo Fernández María Fernanda

Department of Methodological Psychology, Department of Developmental Psychology

University of Santiago de Compostela, Spain

Corresponding Author: Rodríguez González María Soledad, University of Santiago de Compostela Santiago, Compostela, A Coruña Spain or e-mail (msoledad.rodriguez@usc.es). 


\section{Abstract}

The main purpose of this study was to adapt the Student Adaptation to College Questionnaire (SACQ) for use with Spanish students and to examine the psychometric properties of the scores. The adapted version of the scale was applied to a sample of 300 first-year university students. The internal consistency of the full scale and of the subscales was adequate, although the structure of the scale, analyzed by confirmatory factor analysis, did not fit satisfactorily to the four-factor model proposed by Baker and Siryk. The goodness of fit of each of four one-factor models, corresponding to each subscale, was tested separately in order to propose a short form of the scale. The resulting scale, comprising 50 items, shows high internal consistency and the relationships between its dimensions are consistent with those obtained in other studies.

Starting college has been viewed as a major transition in emerging adulthood, in which late adolescents simultaneously develop new patterns of behavioral, cognitive, and affective responses to meet the demands of their new surroundings (Pratt, Hunsberger, Pancer, Alisat, Bowers, Mackey, et al., 2000; Tao, Dong, Pratt, Hunsberger, \& Pancer, 2000). Although most students find the transition to college a challenge to personal growth, many are overwhelmed and experience stress (Wintre \&Yaffe, 2000). The transition can be difficult for many students as they face the new challenges of making personal, academic and social adjustments to the new environment. During the first year at college, students are often confronted with a variety of new demands and changes such as the need to develop learning habits for the new academic environment, coping with new evaluation systems, managing finances, developing new patterns of more mature interpersonal relationships with family members, teachers and classmates, and developing a vocational identity in which processes of decision making, exploration, and commitment are particularly important (Astin, 1993; Tinto, 1996; Parker, Summerfeldt, Hogan, \& Majeski, 2004; Smith \& Renk, 2007; Soares, Guisande, Almeida, \& Páramo, 2009).

There is evidence that the transition to college may be a stressful experience for many first-year students. Several studies have demonstrated that more than half of the students entering higher education experience difficulties in the educational transition (Buote, Pancer, \& Pratt, 2007), with a high incidence of academic problems (Wintre, Bowers, 
Gordner, \& Lange, 2006), emotional problems such as isolation, loneliness, stress and depression (Neto \& Barros, 2000; Tao, et al., 2000; Vazsonyi \& Belliston, 2006), problems in relationships with parents and classmates (Hoffman \& Weiss, 1987; Wintre $\&$ Yaffe, 2000), problems associated with the consumption of alcohol and other psychoactive substances (Caamaño-Isorna, Corral, Parada, \& Cadaveira, 2008), and an increase in psychopathological behavior (Council for the Advancement of Standards in Higher Education, 2006). Analysis of the most recent edition of the Education at a Glance report [Organisation for Economic Co-operation and Development (OECD), 2011] has shown that in Spain more than 50\% of students fail to complete college, and that much of this attrition (approximately 26\%) occurs in the first year. In this regard, Spain occupies one of the worst positions within the European Union. The documented difficulties that students experience during the transition to college, combined with the changing needs of students, have brought increased attention to the academic adjustment of first-year college students and interest in improving graduation rates. The low academic yield, the excessive amount of time invested in degree studies, and the attrition of studies are common problems in all European Union countries (OECD, 2011).

The adjustment to college is considered as multifaceted and involves an array of demands, which vary in kind and degree and require a variety of coping responses or adjustments. Baker and Siryk $(1984,1986,1989)$ developed the Student Adaptation to College Questionnaire (SACQ) to assess how students adjust to college. The SACQ includes 67 items rated on a 9-point scale and comprises four subscales that measure adjustment in four specific areas. The Academic adjustment subscale (24 items) measures the student's success in coping with the various educational demands characteristic of the college experience. The Social adjustment subscale (20 items) measures the student's success in coping with the interpersonal-societal demands inherent in college life. The PersonalEmotional adjustment subscale (15 items) focuses on the student's psychological state and the extent to which he or she is experiencing general psychological distress. The Institutional Attachment subscale (15 items) is designed to measure the student's commitment to educational-institutional goals, the attachment to the particular institution the student is attending, and the quality of the relationship between the student and the institution (Baker \& Syrik, 1989, p. 14-15). Eight of the items included in the scale (Items $1,4,16,26,42,56,57$, and 65 ) contribute to measuring the social adjustment subscale 
and the institutional attachment subscale simultaneously, and one (Item 36) considers both academic adjustment and institutional attachment.

Baker and Siryk (1989) reported the following ranges of Cronbach's coefficients alpha: .92 to .95 for the full scale; .81 to .90 for the Academic adjustment subscale; .83 to .91 for the Social adjustment subscale; .77 to .86 for the Personal-Emotional adjustment subscale; and .85 to .91 for the Institutional Attachment subscale. Correlations between the subscales, and between the subscales and the full scale were significant, with a closer relationship between the Social and Institutional factors (.73) and a lower magnitude relationship between the Social and Academic factors (.42). As regards the dimensionality of the scale, in the SACQ manual, Baker and Siryk (1989) submitted the intercorrelations among subscales to a principal component analysis (PCA) to assess the advantage of the four subscalef' structure over the existence of a single overall adjustment scale. In addition, different studies by the same authors report the excellent criterionrelated and convergent validity of the scale, as a result of the relationships between the dimensions and other variables: grade point average (GPA), social activities, student's use of a Psychological Services Centre, attrition, and so forth, as well as other scales, e.g., measures of personality characteristics, measures of mental health characteristics, measures of environmentally related experiences.

The SACQ has been widely used in North America and constitutes the most important instrument for measuring adjustment to university, and it has also been adapted into other languages. The present study is the first in which a Spanish version of the scale has been adapted for use. However, few studies have addressed the psychometric properties of the SACQ, and most studies merely report the internal consistency of the scale and do not consider the factor structure. Internal domain studies of the SACQ only report the reliability of the scores for the full scale and the four subscales, with Cronbach's alphas above .80. The lack of North American studies investigating the dimensionality of the scale led Taylor and Pastor (2007) to examine the construct validity of scores on the SACQ by confirmatory factor analysis. The results obtained in a sample of 878 students indicated that the four-factor model proposed by the authors of the SACQ provides a poor fit to the data. Due to the poor fit, the authors carried out exploratory factor analysis (EFA), which provided an alternative four-factor model including relevant information for later revisions of the scale. Recently, Feldt, Graham, and Dew (2011) also noted the 
poor fit of Baker and Syrik's model to data from a sample of 305 students. The results of EFA of the data indicated an alternative six-factor model, including the following factors: personal-emotional adjustment, social adjustment, studying, academic adjustment, college adjustment, and institutional adjustment.

Although most studies using the SACQ have been carried out in North America, within Europe the scale has been translated into Dutch(Beyers \& Goossens, 2002), to French (Carayon \& Gilles, 2005), and Portuguese (Rocha \& Matos, 2008). The scale has also been translated into Chinese, and the relationship between adjustment and social support was analyzed in a shortened version of the scale that included 28 items (Jou \& Fukada, 1995; Tao, et al., 2000). Three studies on large European samples (i.e., $N=300$ or more) have examined the internal consistency and factor structure of slightly condensed versions of the SACQ (Beyers \& Goossens, 2002; Carayon \& Gilles, 2005; Rocha \& Matos, 2008). The internal consistency proved satisfactory, but results related to the factor structure were inconsistent. One study (Carayon \& Gilles, 2005) found six factors by means of exploratory factor analysis, whereas another study found support for the hypothesized four-factor structure through confirmatory factor analysis (Rocha \& Matos, 2008).

The original version proposed by Baker and Siryk (1989) and the different applications and adaptations showed that the SACQ scores have psychometric properties that can be considered acceptable, both in terms of internal consistency and in predictive and concurrent validity. However, one of the most important weaknesses of the scale is its internal structure, which does not appear to confirm the model proposed by Baker and Siryk (1989). In addition, the position of some items within different subscales (social adjustment and institutional attachment) does not appear to be supported by he results obtained with the original version of the scale (Taylor \& Pastor, 2007; Feldt, et al., 2011) or the French version (Carayon \& Gilles, 2005). Despite this, the different studies have shown the importance and usefulness of the SACQ in evaluating how students adjust to university. Given the lack of instruments in Spanish to measure this construct, the main purposes of the present study were to translate the Student Adaptation to College Questionnaire (SACQ) for use with Spanish students and to study the psychometric properties of the scale. A further aim of the study was to investigate the dimensionality 
of the scale by examining the structure of the SACQ item scores by use of confirmatory factor analysis.

\section{Method}

\section{Participants}

The sample used in the study consisted of 300 first-year students (198 women, 102 men) attending the University of Santiago de Compostela. The distribution of gender in this sample was representative of the distribution in the overall student population of the university. The participants were drawn at random from different faculties within the five areas of study offered at the University of Santiago de Compostela (Sciences, 32\%; Health Sciences, 20\%; Social Sciences and Law, 25\%; Humanities, 19.7\% and Engineering, 3.3\%).

The mean age of the students was 18.03 years $(S D=0.5$, range $17-20)$. All of the students were selected from a larger sample, by applying the following academic and familyrelated criteria: first-time, first-year attendance at university undertaking full-time courses (60 credits), age less than or equal to 20 years, passed university entrance exams in 2009 , undertaking courses that were their first $(86.7 \%)$ or second choices $(13.3 \%)$, single, and not employed (i.e., they were economically dependent on their parents). A large majority of the students (91\%) were from intact families, and $75.7 \%$ lived in a city other than Santiago de Compostela.

\section{Measures}

The Spanish version of the SACQ was developed by following the steps for the translation and adaptation of tests and scales (Hambleton, 1994, 2005), after a license was obtained from the Western Psychological Services Rights \& Permissions. Translation of the items of the SACQ was conducted by a forward and backward translation design. For the forward translation, two professional translators translated the original version of the scale into Spanish. A meeting involving both of the independent translators and a member from the research group was conducted to review the translation, to achieve conceptual equivalence. The translation agreed upon was then translated back into English by another two independent bilingual translators. Finally, the translators compared the original 
version with the translated English version and made appropriate changes to the items in the Spanish version.

In a pilot study carried out to test the functioning of the Spanish version of the scale, the questionnaire was applied to a sample comprising 277 first year students (246 women, 32 men) attending the University of Santiago de Compostela in the academic year 20082009. Participants rated the 67 items of the Spanish version of the SACQ on a Likert-type 9-point scale ranging from 1: Strongly disagree to 9: Strongly agree, as in the original English version. The order of presentation of the items on the scale was the same as in the original version. The students were also asked to make any suggestions that they considered appropriate as regards any aspect of the questionnaire (i.e., problems related to comprehension, instructions). Analysis of this initial version of the questionnaire led us to reformulate 15 items in order to adapt the content to the context of Spanish university students (Rodríguez, Martínez, Tinajero, Guisande, \& Páramo, 2011). The students also completed a demographic questionnaire that included questions on personal and family details. After these modifications, the resulting version was applied to an independent sample and the results are presented here.

\section{Procedure}

Two members of the research team contacted the students by e-mail to inform them about the objectives of the study. Participation in the study was entirely optional, in line with the ethical code of practice of the Spanish Official Committee of Psychologists. Those students who agreed to participate were invited in groups of 10 to complete the questionnaire and to give signed permission for their data to be used for the purposes of the study, and to confirm their intention to participate in a later phase of the study.

The Spanish version of the SACQ and the demographic questionnaire were administered in the middle of the second term of the academic year by trained researchers. The students were paid $15 €$ for their participation, and the time taken to complete the questionnaire was 30-35 minutes.

\section{Results}

Prior to the analysis, the data were screened for missing responses and outliers. In accordance with the recommendations made by Baker and Siryk (1989), data with three or more missing responses per subscale were excluded from the analysis. For cases with 
two or fewer missing responses, the mean values obtained for the subscale were assigned to those responses. As in the Dutch and French adapted versions of the questionnaire, Items 26 and 33 were omitted, as responses were missing from $24.3 \%$ of the students who were living at home (a higher percentage in Spain and the other European countries than in the U.S.). The response to Item 26, "I enjoy living in a college dormitory," is included in the measures of Social adjustment and Institutional attachment, and Item 33, "I am getting along very well with my roommate(s) at college," is included only in the Social adjustment subscale.

In addition to the subscale scores, a full-scale score was calculated by including the 63 items and a further two items measuring the overall adjustment to university life (Items 53 "I feel I have good control over my life situation at college" and 67 "I feel confident that I will be able to deal in a satisfactory manner with future challenges here at college"). The scores for the subscales Academic adjustment (24 items), Social adjustment (18 items), Personal-emotional adjustment (15 items), and Goal commitment/ Institutional attachment (14 items) were also calculated. Items 1, 4, 16, 42, 56, 57, and 65 contribute to scores on Social adjustment and Institutional attachment simultaneously, and Item 36 is included in both Academic adjustment and Institutional attachment. Intercorrelations between the subscale scores and the full scale score are shown in Table 1. All Pearson's correlations were significant $(p<.05)$, and showed a stronger relationship between the Social and Institutional factors $(r=.79, p<.001)$, and a weaker relationship between Personal-Emotional adjustment and Institutional Attachment $(r=.47, p<.001)$.

The mean values, standard deviations, and reliability coefficients are also shown in Table 1. Taking into account the number of items, the present results indicate that Spanish students had higher scores on Institutional attachment than other types of adjustment, as also found in American samples ( $M$ scores $>7)$. The distribution of the scores for the 6 items that measured only the Institutional component showed negative asymmetry and high kurtosis values, although they were only very high for Items 60 and 61 (kurtosis > 8). McDonald's omega and Cronbach's alpha were robust, with coefficients higher than .90 for the full-scale and higher than .80 for the different subscales.

Scale Dimensionality 
The structure of the SACQ was analyzed by confirmatory factor analysis (CFA), applied to the scores obtained for the 63 items that contributed to measuring the four factors considered in adjustment to university. The CFA was conducted by using LISREL 8.8 (Jöreskog \& Sörbom, 1996), with the covariance matrices produced by PRELIS. Before conducting the analyses, univariate distributions were examined for multivariate normality (Mardia's normalized coefficient of multivariate kurtosis $=4,649.09$ ). The

skewness values were higher than 3.0 and kurtosis values higher than 10 for Items 60 and 61, suggesting a problem of non-normality (Kline, 1998). The robust maximum likelihood estimation method was used to analyze the models. To evaluate the model fits, the chi-squared values (Satorra- Bentler scaled chi-square), the $\chi 2 / d f$ ratio, root mean square error of approximation (RMSEA), comparative fit index (CFI), and the standardized root mean square residual (SRMR) were examined simultaneously. As recommended by $\mathrm{Hu}$ and Bentler (1999), values of $\mathrm{RMSEA}<.06, \mathrm{CFI}>.95, \mathrm{SRMR}<$ .08 and $\chi 2 / d f$ ratio $<3$ indicate an acceptable model fit.

The fit of the four-factor model proposed by Baker and Siryk (1989) was analyzed (see Table 2). Taking into account the reference criteria suggested by Hu and Bentler (1999), the results of the confirmatory factor analysis indicate that the four-factor model did not fit adequately to the data, which is consistent with the results obtained by Taylor and Pastor (2007) with the original English version of the questionnaire. However, if more flexible criteria are considered, most of the fit statistics appear to be acceptable, as values $<.08$ for RMSEA (.07), values > .90 for CFI (.91), and values $\chi 2 / d f$ ratio $(2.72)<3$ indicate an acceptable fit (Browne \& Cudeck, 1993; Marsh, Hau, \& Wen, 2004).

To detect areas of poor fit and to improve the model fit, the one-factor models were tested separately for each subscale. Only the model for the Personal-Emotional adjustment subscale showed an acceptable fit, and the other subscales showed poor fits (Table 2).

In light of the results for the different models analyzed, a more parsimonious version of the model, based on parameter estimates for the four factor model, was proposed. For the re-specification, the standardized coefficients (see Table 3 and the Appendix, pp. 638640), the standardized residuals, and the modification indices were examined in conjunction with the substantive and contextual aspects. 
Firstly, the items that in the original scale were assigned to various factors were eliminated from the factor in which they displayed a standardized path coefficient lower than .30 (Kline, 1998). This mainly affected the Institutional attachment subscale, which in the original version shared items with the Social and Academic adjustment subscales. As in other studies (Taylor \& Pastor, 2007; Feldt, et al. 2011), the results did not support these items that were included in two factors, as seven of these (Items 1, 4, 36, 42, 56, 57 , 65) displayed standardized coefficients $<.30$ (range .00 to .24) in the Institutional attachment factor, and the highest loading (.71) was found for the Institutional attachment factor, rather than for the Social adjustment factor (.08), only in Item 16. Furthermore, the six items that contributed in the original scale to measuring only the Institutional factor showed standardized coefficients $>.60$ were, therefore, adequate indicators of this component of adjustment. Secondly, items that yielded low structural coefficients and failed to reach statistical significance were omitted (Items 6 and 23 on Academic factor, Items 14, 22, 48 and 56 on Social factor, Items 24, 35 and 49 on Personal factor). Four items (Items 14, 24, 35 and 49) also loaded poorly, as in the studies by Feldt, et al. (2011) and Taylor and Pastor (2007). In addition, the results for Item 6 were consistent with those reported by Feldt, et al. (2011), and those for Items 48 and 49 were consistent with those reported by Taylor and Pastor (2007).

Thirdly, items that had secondary loadings on others factors were omitted (Items 3, 10, 17, 25, 36, and 39). These items loaded on the Academic dimension of adjustment, which indicates the difficulty in isolating strong indicators of this component in the context of the study, given the close relationship with other components of adjustment. The modification indices indicate that Items 10, 39, and 25 also have high loadings on Personal adjustment, Item 36 on Social and Institutional adjustment, and Items 3 and 17 on all factors. The results for Items 10, 39, and 36 are consistent with those reported by Taylor and Pastor (2007). Finally, within the Academic adjustment subscale, Item 5, "I know why I'm in college and what I want out of it," was reassigned to the Institutional attachment factor as the standardized coefficient was higher for the latter factor (.65), as well as the relation with the subscale score $(r=.55)$. The values of standardized residuals for Item 66, "I'm quite satisfied with my academic situation at college," and the items of Academic adjustment were high (>9). Therefore, this item can be used as a measure of the overall adjustment, along with Items 53 and 67, with which it is closely related $(r s=$ .61 and .48 , respectively). 
The short version of the Spanish SACQ, considering only the 47 items scores that contribute to the subscale factors, fitted adequately to the four factor model proposed by Baker and Siryk (1989), and substantially improved the goodness-of-fit index of the original model, as it reached the critical values suggested by $\mathrm{Hu}$ and Bentler (1999) (see Table 2). The parameter estimates for the short version of SACQ (see Table 3) were statistically significant, and the relationships between the factors ranged from .39 for the Institutional vs Personal subscales, to .77 for the Institutional vs Academic subscales. In addition, the reliability (Cronbach's alpha and Mc-Donald's omega) of the scores was similar to that obtained for the initial version, with coefficients of .95 for the full-scale and above .80 for the different subscales. The Academic adjustment subscale, with only 14 of the 25 original items, underwent the greatest modification, as the unifactorial model provided one of the poorest fits and this dimension was strongly related to other components of adjustment to university life.

\section{Discussion}

Considering the model proposed by Baker and Siryk (1989), the Spanish version of the SACQ (65 items) displayed good internal consistency, $\alpha>.90$ for the full-scale scores and $\alpha>.80$ for the different subscales. Intercorrelations between subscales and the full scale score were significant, with the dimensions Social adjustment and Institutional attachment (which have 7 items in common) being most closely related, and the dimensions Personal adjustment and Institutional attachment the least closely related.

As in previous studies carried out with both the original and adapted versions, confirmatory factor analysis based on covariances between the subscales led to rejection of the one-factor model, indicating the interest in maintaining the subscales, as concluded by the authors of the original SACQ.

Confirmatory factor analysis was used to test the fit of the four-factor model proposed by the authors of the SACQ, as well as the fits of the one-factor models for each subscale. The dimensionality of the scale, questioned by Taylor and Pastor (2007) in a study involving a sample of American students, was also found to be problematic in the present study, although when more flexible fit criteria were considered, the fit to the four-factor model was tolerable, given the complexity of the model. A detailed examination of the different solutions obtained suggested the need to modify the scale further. The 
modifications required in the adapted versions are partly due to the differences in organization of American and European university studies as regards mode of access, the higher percentage of European University students who live at home, as well as the university context. However, the results obtained also support other actions aimed at improving the fit of the scale to the model and at improving the scale itself, as many of the items are factorially complex, and others are redundant or of little importance in the context of Spanish university students.

Firstly, the present results did not support the assignment of some items to various factors (Social adjustment and Institutional attachment), as also found in previous studies. In addition, re-assignment of two items, and the removal of 15 items from the scale was recommended because the structural coefficients associated with the factor are low or because they loaded on multiple factors. Such actions, aimed at shortening the scale and revising it conceptually to improve the psychometric properties, are consistent with those carried out or suggested in other studies. On one hand, the two studies carried out with the original version and EFA concluded the need to revise the scale, particularly as regards 20 of the items according to Taylor and Pastor (2007), largely in agreement with the changes indicated by Feldt, et al. (2011). On the other hand, the authors of the French adaptation proposed a shortened version, in which 13 of the items were eliminated. Many of the same items were found to be problematic in the present study, suggesting that beyond cultural and contextual differences, it is possible to measure adaptation to university with a simpler instrument, but still from the theoretical perspective of Baker and Siryk (1989). In this sense, the shortened Spanish version of the SACQ, composed of 50 items, provided a better fit and constituted a suitable instrument in the context of the present study, and provided adequate guarantees of reliability and validity for measuring how first-year university students adapt to university. In addition, the proposed elimination enabled better definition of the four dimensions of adjustment to university.

The present results identify items in the Academic adjustment subscale that are the most problematic and should be considered in greater detail. For this purpose, external validation of the students' responses, using objective indicators and not only self-reported measures, is required to ensure that the items included in the scale are adequate for predicting academic results, examining their relation to grade point average (GPA), attrition, and also other indicators of students' academic success or failure. 
This study has specific limitations. The adapted version of the SACQ, which constitutes a substantially modified model, should be cross-validated in a larger, independent sample (Henson \& Roberts, 2006). Sample sizes of 200 to 500 are probably sufficient for good estimates with "robust"statistics, but sample sizes of over 500 may be best, given the large number of items on the scale. On the other hand, external evidence is required to clarify the meaning and utility of the subscale scores, so that further research on the predictive validity of the Spanish version of the SACQ is essential.

Finally, the present study would have benefited from the addition of qualitative data. Correct evaluation of academic adjustment requires complementing the measures obtained with personal interviews. Such interviews would clarify the themes and delineate the factors influencing academic adjustment.

Despite these limitations, certain strengths were identified in the study. For example, this is first study that has applied the SACQ to a sample from a Spanish University. Moreover, data from research using the SACQ provides a basis for identifying factors that influence the effectiveness of adjustment to college. Finally, in terms of practical applications, the results provide the basis for a support program to identify students who are at risk of adjusting poorly during their first year of college or university.

\section{References}

Astin, A. (1993) What matters in college? Four critical years revised. San Francisco: Jossey-Bass.

Baker, R. W., \& Siryk, B. (1984) Measuring adjustment to college. Journal of Counseling Psychology, 31, 179-189.

Baker, R. W., \& Siryk, B. (1986) E xploratory intervention with a scale measuring adjustmentto college. Journal of Counseling Psychology, 33, 31-38.

Baker, R. W., \& Siryk, B. (1989) Student Adaptation to College Questionnaire (SACQ): manual. Los Angeles: Western Psychological Services. 
Beyers, W., \& Goossens, L. (2002) C oncurrent and predictive validity of student adaptation to college questionnaire in a sample of European freshman students. Educational and Psychological Measurement, 62, 527-538.

Browne, M. W., \& Cudeck, R. (1993) Alternative ways of assessing model fit. In K. A.

Bollen \& J. S. Long (Eds.), Testing structural equation models. Newbury Park, CA:

Sage. Pp. 136-162.

Buote, V. M., Pancer, S. M., \& Pratt, M. W. (2007) T he importance of friends among 1st-year university students. Journal of Adolescent Research, 22, 665-689.

Caamaño-Isorna, F., Corral, M., Parada, M., \& Cadaveira, F. (2008) Factors associated with risky consumption and heavy episodic drinking among Spanish university students. Journal of Studies on Alcohol and Drugs, 69, 308-312.

Carayon, S., \& Gilles, P. (2005) Développement du questionnaire d'adaptation des étudiants à l'université (Q.A.E.U.) [Development of the Adaptation Questionnaire for University Students (AQUS)]. L’ orientation Scolaire et Professionnelle, 34, 165-189.

Council for the Advancement of Standards in Higher Education. (2006) Self-assessment guide for counseling services. Washington: Author.

Feldt, R. C., Graham, M., \& Dew, D. (2011) Measuring adjustment to college: construct validity of the Student Adaptation to College Questionnaire. Measurement and Evaluation in Counseling and Development, 44, 92-104.

Hambleton, R. K. (1994) G uidelines for adapting educational and psychological tests: a progress report. European Journal of Psychological Assessment, 10, 229-244.

Hambleton, R. K. (2005) I ssues, designs, and technical guidelines for adapting tests into multiple languages and cultures. In R. K. Hambleton, P. F. Merenda, \& S. D.

Spielberger (Eds.), Adapting educational and psychological tests for cross-cultural assessment. Hillsdale, NJ: Erlbaum. Pp. 3-38. 
Henson, R. K., \& Roberts, J. K. (2006) Use of exploratory factor analysis in publishedresearch: common errors and some comment on improved practice. Educational and Psychological Measurement, 66, 393-416.

Hoffman, J. A., \& Weiss, B. (1987) Family dynamics and presenting problems in college students. Journal of Counseling Psychology, 34, 157-163.

Hu, L., \& Bentler, P. M. (1999) Cutoff criteria for fit indexes in covariance structure analysis: conventional criteria versus new alternatives. Structural Equation Modeling, 6, 1-55.

Jöreskog, K. G., \& Sörbom, D. (1996) LISREL 8: user’’s reference guide. Lincolnwood, IL: Scientific Software International.

Jou, Y. H., \& Fukada, H. (1995) Effect of social support on adjustment of Chinese students in Japan. Journal of Social Psychology, 135, 39-47.

Kline, R. B. (1998) Principles and practice of structural equation modeling. New York: Guilford.

Marsh, H. W., Hau, K., \& Wen, Z. (2004) In search of golden rules: comment on hypothesis- testing approaches to setting cutoff values for fit indexes and dangers in overgeneralizing $\mathrm{Hu}$ and Bentler's (1999) findings. Structural Equation Modeling, 11, 320-341.

Neto, F., \& Barros, J. (2000) Psychosocial concomitants of loneliness among students of Cabo Verde and Portugal. Journal of Psychology, 134, 503-514.

Organisation for Economic Co-operation and Development. (2011) Education at a glance: OECD indicators. Paris: Author.

Parker, J. D. A., Summerfeldt, L. J., Hogan, M. J., \& Majeski, S. A. (2004) Emotional intelligence and academic success: examining the transition from high school to university. Personality and Individual Differences, 36, 163-173.

Pratt, M. W., Hunsberger, B., Pancer, S., Alisat, S., Bowers, C., Mackey, K., Ostaniewicz, A., Rog, E., Terzian, B., \& Thomas, N. (2000) Facilitating the transition to university: evaluation of a social support discussion intervention program. Journal of College Student Development, 41, 427-441. 
Rocha, M., \& Matos, P. M. (2008) A daptaçao do Student Adaptation to College Questionnaire (SACQ) a uma amostra de adolescentes de escolas regulares, profissionais e pólos de aprendizagem [Adaptation of the Student Adaptation to College Questionnaire (SACQ) in a sample of adolescents from regular schools, professional schools, and apprenticeship training programs]. Psicologia, Educaçao e Cultura, XII, 171-196.

Rodríguez, M. S., Martínez, Z., Tinajero, C., Guisande, M. A., \& Páramo, M. F. (2011) Dimensionality of the "Student Adaptation to College Questionnaire" in a Spanish sample. Paper presented at the 12th European Congress of Psychology, Istanbul, Turkey.

Smith, T., \& Renk, K. (2007) Predictors of academic-related stress in college students: an examination of coping, social support, parenting, and anxiety. NASPA Journal, 44, 405-431. [Electronic version]

Soares, A. P., Guisande, M. A., Almeida, L. S., \& Páramo, M. F. (2009) A cademic achievement in first-year Portuguese college students: the role of academic preparation and learning strategies. International Journal of Psychology, 44, 204212.

Tao, S., Dong, Q., Pratt, M. W., Hunsberger, B., \& Pancer, S. M. (2000) S ocial support: relations to coping and adjustment during the transition to university in the People's Republic of China. Journal of Adolescent Research, 15, 123-144.

Taylor, M. A., \& Pastor, D. A. (2007) A confirmatory factor analysis of the Student Adaptation to College Questionnaire. Educational and Psychological Measurement, 67, 1002-1018.

Tinto, V. (1996) Persistence and first-year experience in the community college: teaching new students to survive, stay, and thrive. In J. N. Hankin (Ed.), The community college: opportunity and access for America's sirst year students (Monograph No. 19). Columbia, SC: Univer. of South Carolina, The National Resource Center for the Freshman Year Experience \& Students in Transition. Pp. 97-104. 
Vazsonyi, A. T., \& Belliston, L. M. (2006) The cultural and developmental significance of parenting processes in adolescent anxiety and depression symptoms. Journal of Youth and Adolescence, 35, 491-505.

Wintre, M. G., Bowers, C., Gordner, N., \& Lange, L. (2006) R e-evaluating the university attrition statistic: a longitudinal follow-up study. Journal of Adolescence Research, 21, 111-132.

Wintre, M. G., \& Yaffe, M. (2000) First-year students' adjustment to university life as a function of relationships with parents. Journal of Adolescent Research, 15, 9-91. 


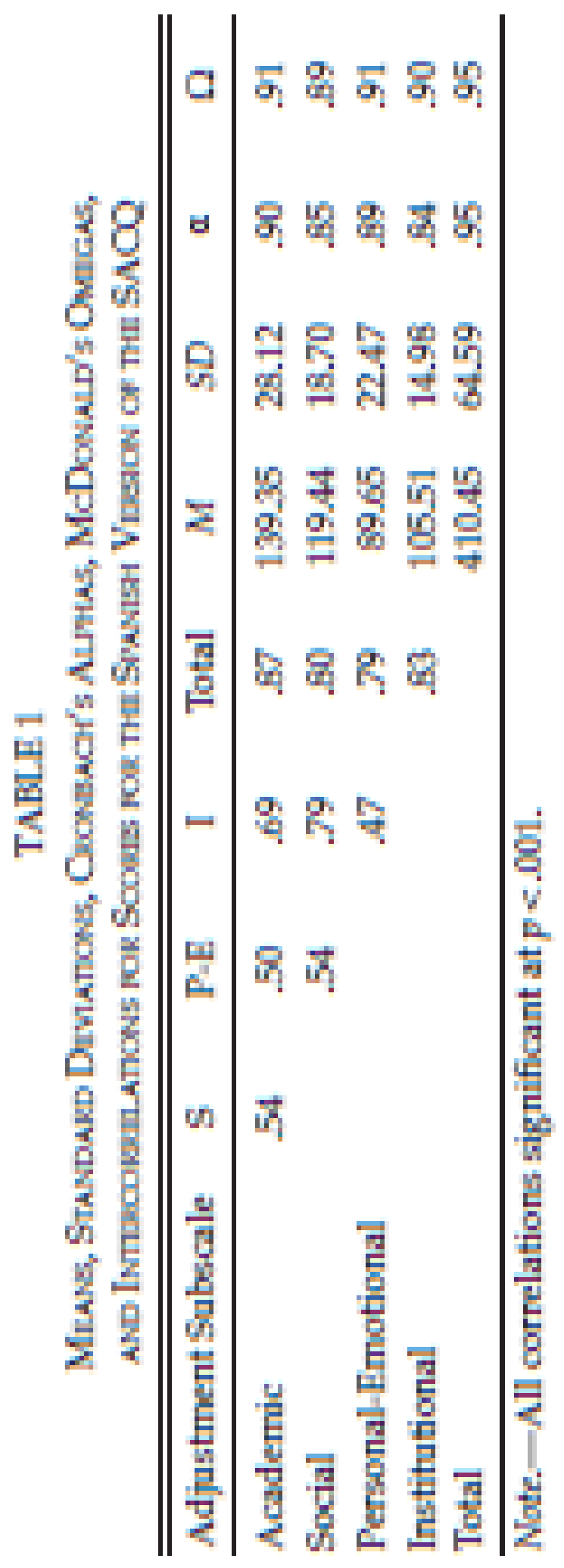




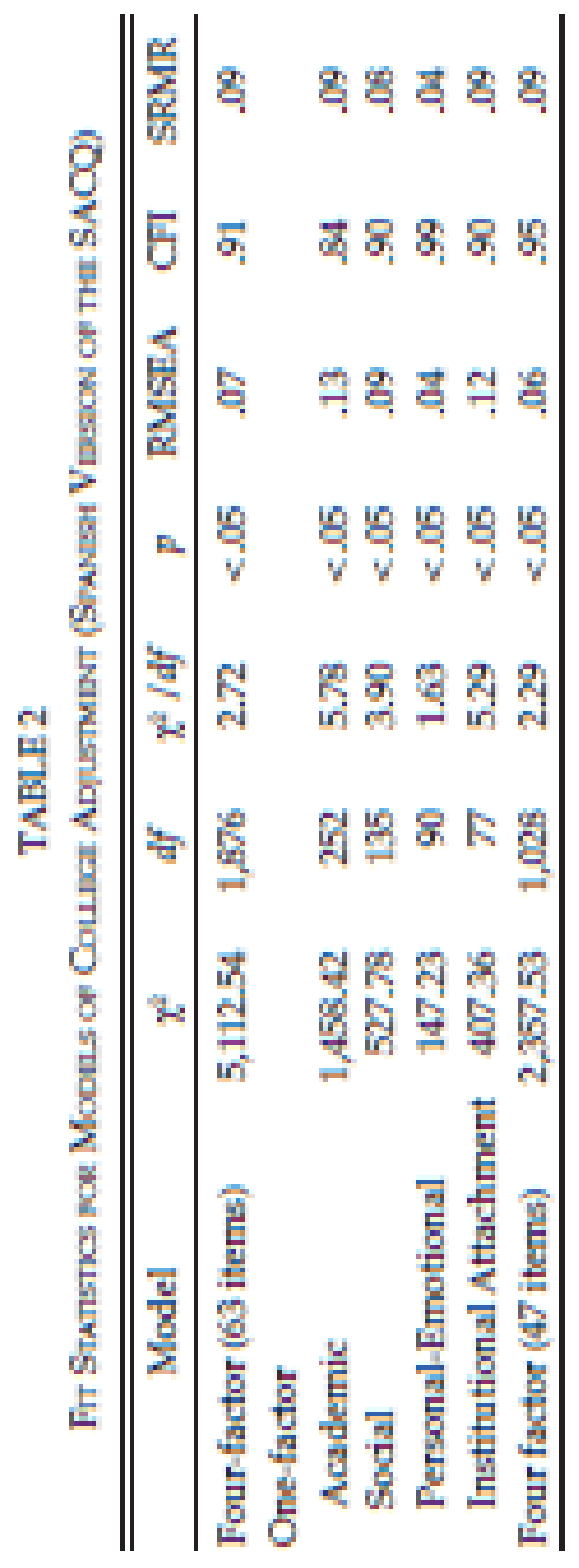




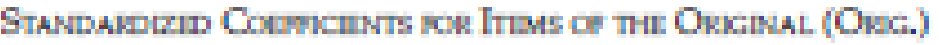

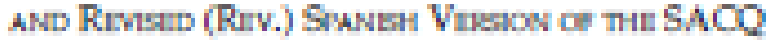

\begin{tabular}{|c|c|c|c|c|c|c|c|c|c|c|c|}
\hline \multicolumn{3}{|c|}{ Acsdemic } & \multicolumn{3}{|c|}{ Sorial } & \multicolumn{3}{|c|}{ Insthtutional } & \multicolumn{3}{|c|}{ Personal-Emotional } \\
\hline \multirow[t]{2}{*}{ Item } & \multicolumn{2}{|c|}{$\begin{array}{l}\text { Standardired } \\
\text { Coefficients }\end{array}$} & \multirow[t]{2}{*}{ Item } & \multicolumn{2}{|c|}{$\begin{array}{l}\text { Sandardized } \\
\text { Coefficients }\end{array}$} & \multirow[t]{2}{*}{ Item } & \multicolumn{2}{|c|}{$\begin{array}{l}\text { Standandied } \\
\text { Coefficients }\end{array}$} & \multirow[t]{2}{*}{ Ttem } & \multicolumn{2}{|c|}{$\begin{array}{l}\text { Standardized } \\
\text { Coefficients }\end{array}$} \\
\hline & Oris. & Rev: & & Orig- & Rev. & & Oris. & Rev: & & Orig- & Rev. \\
\hline$A 7$ & 54 & & S1 & .61 & .78 & $\$ 1$ & 24 & & $\mathbf{m} 2$ & .69 & $\Delta$ \\
\hline$A 5$ & 41 & & 54 & 76 & 65 & 54 & -.16 & & $\mathrm{P} 7$ & .88 & $B 5$ \\
\hline$A B \bar{~}$ & 25 & & S & 51 & 51 & & & & P11 & 55 & 55 \\
\hline A10 & 61 & & s9 & .81 & 83 & & & & $\mathrm{P} 12$ & 56 & 55 \\
\hline A13 & .61 & .48 & S14 & 25 & & & & & P20 & .7 & 7 \\
\hline$A 17$ & 50 & & Sl6 & .06 & & 516 & 71 & $\pi$ & $\mathrm{F} 24$ & 28 & \\
\hline A19 & .55 & 56 & S16 & 49 & 49 & & & & P28 & .47 & -47 \\
\hline $\mathrm{A} 21$ & .49 & .44 & 822 & 25 & & & & & $\mathbf{P a 1}$ & 57 & 57 \\
\hline$A 27$ & -18 & & $5 \%$ & 30 & 34 & & & & P35 & 30 & \\
\hline$A 25$ & .59 & & 537 & .60 & .57 & & & & Pas & .69 & 69 \\
\hline$A 27$ & 42 & .45 & $S 42$ & .56 & 49 & $\$ 42$ & -.10 & & P40 & 59 & 59 \\
\hline$A 29$ & .67 & .65 & 546 & 30 & 33 & & & & P45 & 75 & .75 \\
\hline $\mathrm{A} 32$ & 41 & .46 & 548 & 25 & & & & & P49 & 28 & \\
\hline$A x$ & .45 & & 551 & 66 & 63 & $A x$ & .16 & & P55 & . 3 & $B 3$ \\
\hline$A 99$ & .58 & & 556 & 25 & & 556 & .00 & & PQ4 & .65 & .65 \\
\hline M41 & .54 & 48 & 567 & 36 & 44 & 557 & .11 & & & & \\
\hline $\mathrm{M} 3$ & .54 & .60 & 863 & .55 & .53 & & & & & & \\
\hline $\mathrm{A} 4$ & 52 & .49 & 86 & $\pi$ & 80 & 565 & .12 & & & & \\
\hline A50 & 65 & 71 & & & & $\mathrm{I15}$ & 71 & 7 & & & \\
\hline A52 & 41 & 34 & & & & $\mathrm{IM}$ & 70 & .66 & & & \\
\hline A54 & .67 & 71 & & & & I47 & 71 & 71 & & & \\
\hline A5s & 60 & .66 & & & & 159 & 77 & 76 & & & \\
\hline $\operatorname{sb2}$ & .51 & 55 & & & & I60 & .55 & 53 & & & \\
\hline \multirow[t]{2}{*}{ Ab6 } & $\omega 6$ & & & & & I61 & .60 & .58 & & & \\
\hline & & & & & & A5 & & .65 & & & \\
\hline a & .85 & & & .95 & & & .90 & & & .86 & \\
\hline $\mathrm{a}$ & 86 & & & .84 & & & .92 & & & .84 & \\
\hline
\end{tabular}

Note-Items omitted from the sale are shown in italics. Cronbach's alpha and MeDonald's omega for the short version. 


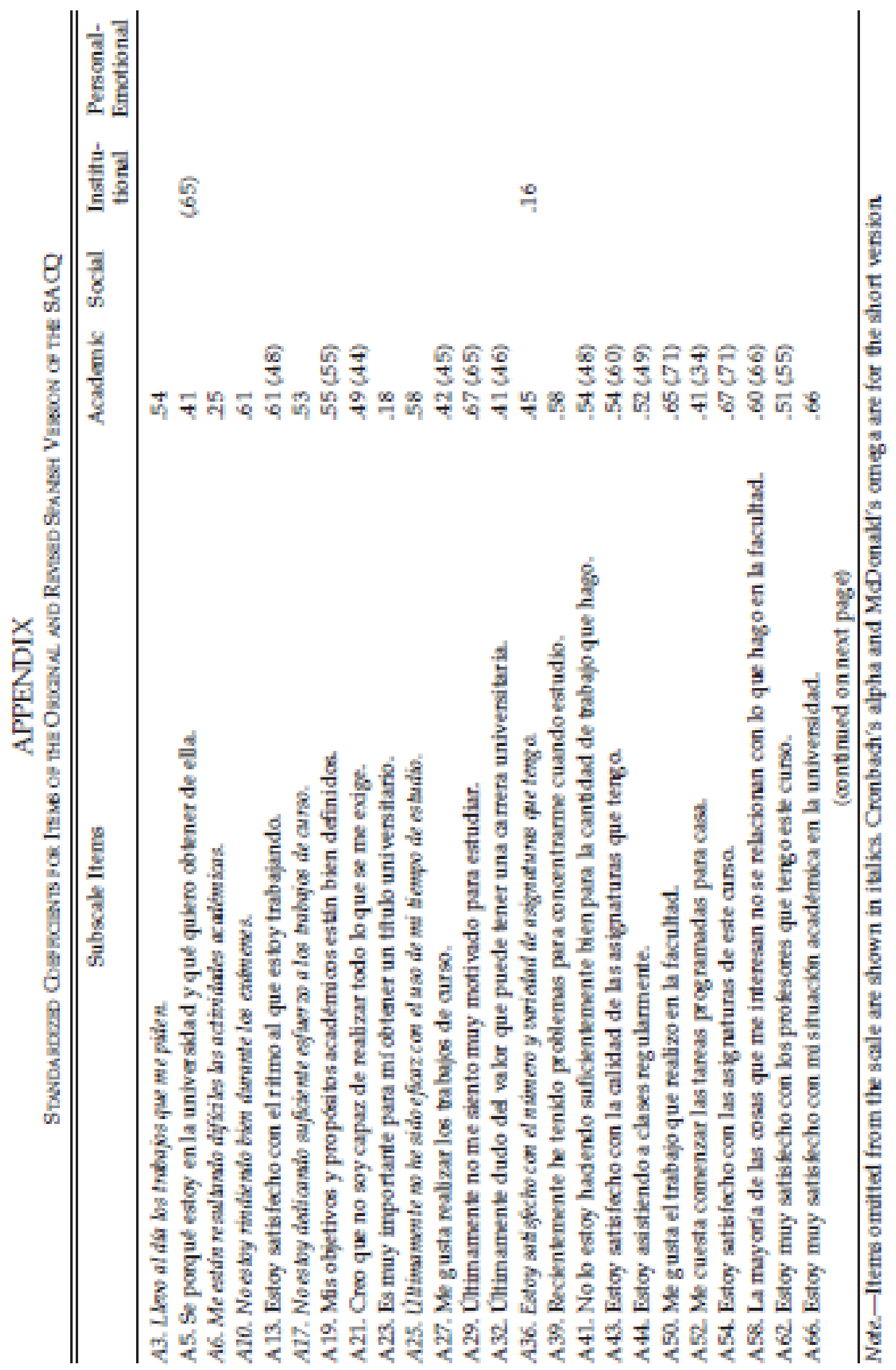




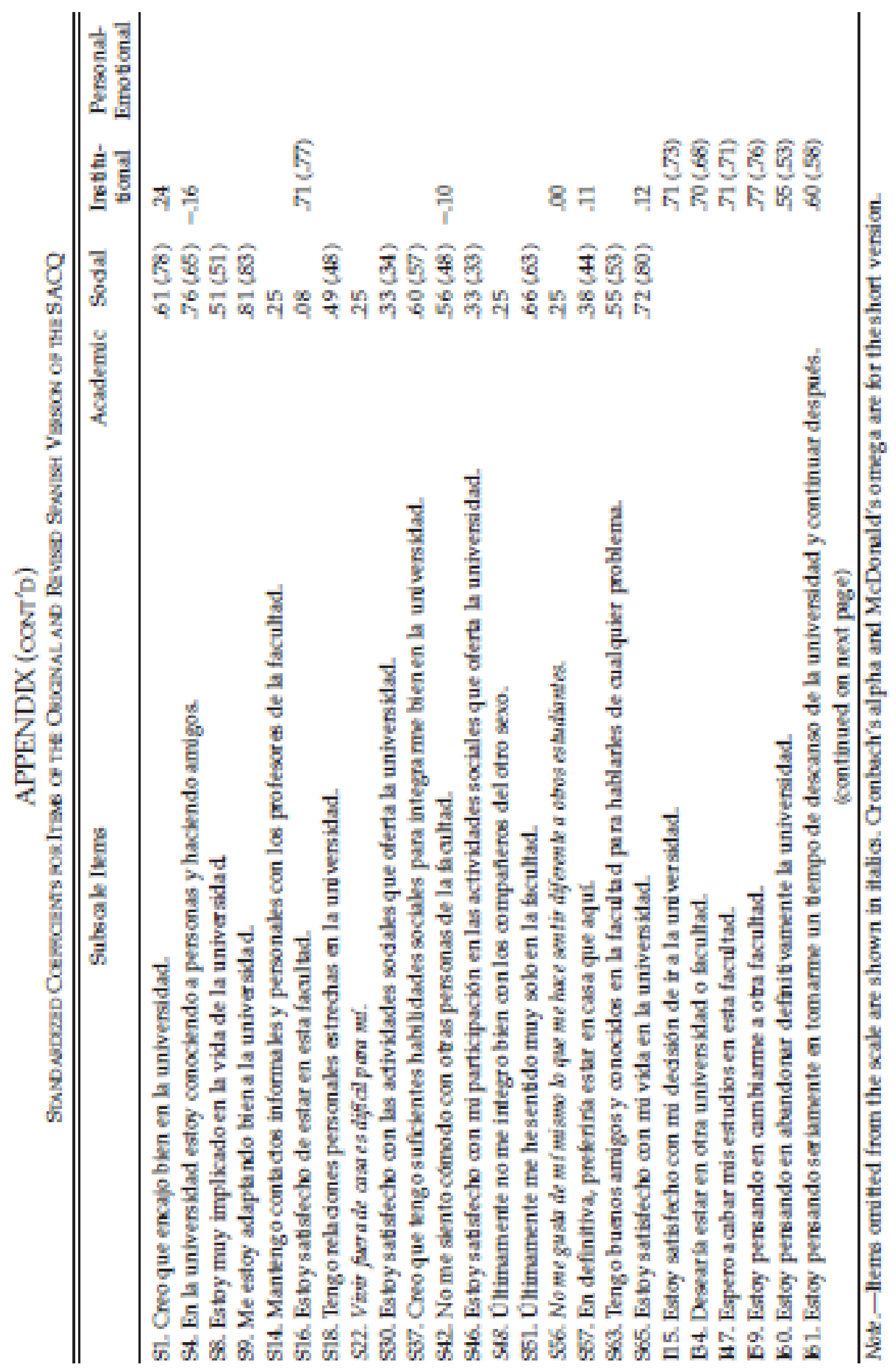




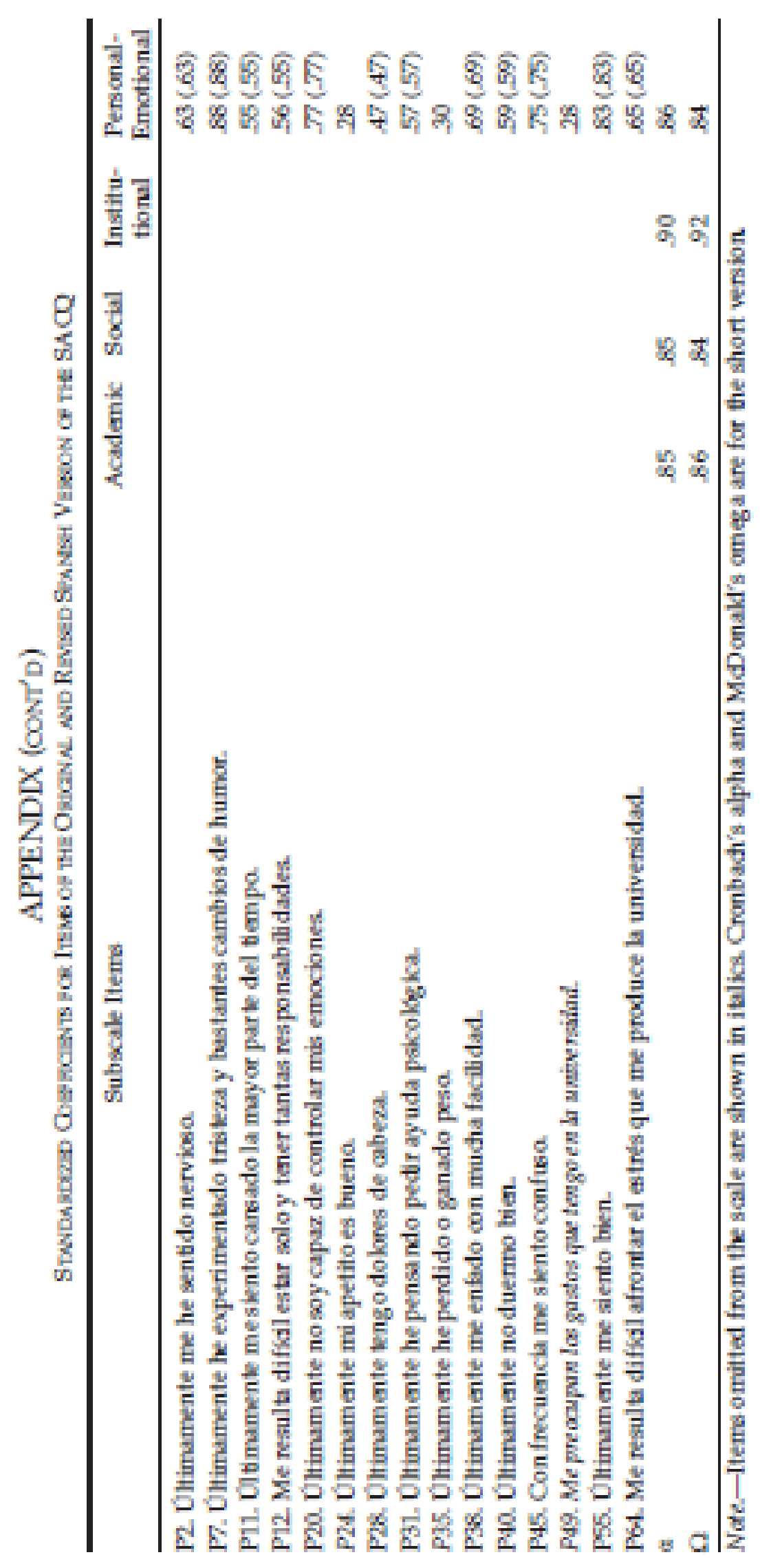

